\title{
Effects of eugenol on resting tension of rat atria
}

\author{
R.R. Olivoto, C.E.N. Damiani, I. Kassouf Silva, M.S. Lofrano-Alves, M.A. Oliveira and R.T.H. Fogaça \\ Departamento de Fisiologia, Universidade Federal do Paraná, Curitiba, PR, Brasil
}

\begin{abstract}
In cardiac and skeletal muscle, eugenol ( $\mu \mathrm{M}$ range) blocks excitation-contraction coupling. In skeletal muscle, however, larger doses of eugenol (mM range) induce calcium release from the sarcoplasmic reticulum. The effects of eugenol are therefore dependent on its concentration. In this study, we evaluated the effects of eugenol on the contractility of isolated, quiescent atrial trabeculae from male Wistar rats $(250-300 \mathrm{~g} ; \mathrm{n}=131)$ and measured atrial ATP content. Eugenol $(1,3,5,7$, and $10 \mathrm{mM})$ increased resting tension in a dose-dependent manner. Ryanodine [100 $\mu \mathrm{M}$; a specific ryanodine receptor (RyR) blocker] and procaine (30 mM; a nonspecific RyR blocker) did not block the increased resting tension induced by eugenol regardless of whether extracellular calcium was present. The myosin-specific inhibitor 2,3-butanedione monoxime (BDM), however, reversed the increase in resting tension induced by eugenol. In Triton-skinned atrial trabeculae, in which all membranes were solubilized, eugenol did not change resting tension, maximum force produced, or the force $v s \mathrm{pCa}$ relationship ( $\mathrm{pCa}=-\mathrm{log}$ $\left.\left[\mathrm{Ca}^{2+}\right]\right)$. Given that eugenol reduced ATP concentration, the increase in resting tension observed in this study may have resulted from cooperative activation of cardiac thin filaments by strongly attached cross-bridges (rigor state).
\end{abstract}

Key words: Eugenol; Atrial trabeculae; Resting tension; Ryanodine; Rat; ATP

\section{Introduction}

In cardiac muscle, excitation-contraction coupling (ECC) is mediated by $\mathrm{Ca}^{2+}$ influx through voltage-gated $\mathrm{Ca}^{2+}$ channels (dihydropyridine receptors, DHPRs). This limited $\mathrm{Ca}^{2+}$ entry triggers a massive $\mathrm{Ca}^{2+}$-induced $\mathrm{Ca}^{2+}$ release $(\mathrm{CICR})$ from the sarcoplasmic reticulum $(\mathrm{SR})$, a process that leads to activation of contractile proteins and cardiac muscle contraction (1). It is well established that CICR is mediated by the ryanodine receptors (RyRs) of $\mathrm{Ca}^{2+}$ release channels on the membrane of the SR $(2,3)$. Eugenol [2-methoxy-4-(2propenyl)phenol], an essential oil extracted from crotonclover and the chief component of clove oil, is frequently used in the food industry, in aromatherapy, and as a therapeutic agent in dentistry (4-7).

Experimental studies have demonstrated that eugenol has a broad range of biological effects. For example, at low concentrations (0.01-0.5 mM), eugenol reduces the force produced by electrically paced intact papillary muscles in rat and guinea pig model systems $(8,9)$. The authors suggest that this effect is likely due to blockage of the L-type calcium channel.

This hypothesis is supported by a study that used the whole-cell configuration patch clamp technique on the
L-type $\mathrm{Ca}^{2+}$ current in isolated canine and human ventricular cardiomyocytes (10). Furthermore, in skeletal muscle of toads, eugenol (at low concentrations) blocked contraction induced by a high-potassium Ringer solution, but potentiated the effect of caffeine (an RyR agonist) (11).

In the same study, however, high concentrations of eugenol (mM range) induced muscle contraction per se. Skeletal muscle contraction induced by eugenol likely involves calcium release from the SR through RyR and a heparin-sensitive pathway (12). This suggests that the effects of eugenol are dependent on the concentration used. However, in cardiac muscle, there have been no studies using eugenol in the millimolar range as has been conducted in skeletal muscle fibers. Thus, we evaluated the effects of eugenol on the contractility of isolated atrial trabeculae from the rat and measured the concentration of ATP. We found that eugenol increased the resting tension in a dose-dependent manner.

Ryanodine [100 $\mu \mathrm{M}$; a specific ryanodine receptor (RyR) blocker] and procaine (30 mM; a nonspecific RyR blocker) did not block the increase in resting tension induced by eugenol regardless of whether extracellular

Correspondence: R.R. Olivoto, Rua Paraná, 1643, 85960-000 Marechal Candido Rondon, PR, Brasil. E-mail: robsonolivoto@ yahoo.com.br

Received September 12, 2013. Accepted February 3, 2014. First published online March 21, 2014. 
calcium was present. In Triton-skinned trabeculae, in which all membranes were solubilized, eugenol did not change the resting tension, the maximum force produced, or the force vs $\mathrm{pCa}$ relationship ( $\mathrm{pCa}=-\log \left[\mathrm{Ca}^{2+}\right]$ ). However, eugenol decreased ATP content in atrial muscle.

\section{Material and Methods}

All procedures and techniques used in this study were conducted following the guidelines of the Declaration of Helsinki for the care and use of laboratory animals, and were approved by the Animal Experimentation Ethics Committee of the Setor de Ciências Biológicas, Universidade Federal do Paraná (CEEA, \#231, process \#23075-021110/2007). Male Wistar rats (250-300 g; $\mathrm{n}=131$ ) were anesthetized with $45 \mathrm{mg} / \mathrm{kg}$ sodium pentobarbital intraperitoneally (ip). Hearts were removed immediately following thoracotomy and perfused with normal Ringer solution through the aortic stump to permit proper selection and dissection of the atrial muscles. The muscle ends were mounted between two forceps. One end was connected to an isometric force transducer (Scientific Instruments, GMBH, Germany) and the other end was connected to a micromanipulator. Trabeculae dimensions were measured using a reticule and a dissecting microscope. The output of the force transducer was fed into a strip-chart recorder (model RB 1020, Equipamentos Científicos do Brasil, Brazil) and a data acquisition system (Power Lab, USA) coupled to a computer for graphical analysis. Muscles were then immersed in 15-mL Ringer solution that was maintained at $30 \pm 1^{\circ} \mathrm{C}$ and gassed with $100 \%$ oxygen (see below). Muscles stretched to $L_{\max }$ (muscle length at which active tension is maximal) were stimulated by isolated rectangular pulses (10-15 V, 12 ms duration) through a pair of platinum electrodes placed along the entire extended length of the muscle. The standard stimulation rate was $0.5 \mathrm{~Hz}$. Recording started after $60 \mathrm{~min}$ to permit the beating preparation to adapt to the new environmental conditions. In normal Ringer solution, the twitch was used to test the efficacy of the drugs used (procaine or ryanodine). After the tension reached steady state, electrical stimulation was stopped and $5 \mathrm{mM}$ eugenol, with or without $100 \mu \mathrm{M}$ ryanodine, and/or $10 \mathrm{mM}$ procaine, was added to the solution. In another series of experiments, the drugs were added to calcium-free Ringer solution.

The bathing solution was normal Ringer solution, which included $110 \mathrm{mM} \mathrm{NaCl}, 4 \mathrm{mM} \mathrm{KCl}, 2 \mathrm{mM} \mathrm{CaCl}_{2}$, $2 \mathrm{mM} \mathrm{MgCl}_{2}, 10 \mathrm{mM}$ Trizma, and $11 \mathrm{mM}$ glucose. The $\mathrm{pH}$ was adjusted to 7.4. Calcium was omitted to obtain calcium-free Ringer solution. Stock solutions of $10 \mathrm{mM}$ ryanodine (dissolved in ethanol) and $100 \mathrm{mM}$ eugenol (dissolved in distilled water) were added directly to the Ringer solution to obtain final concentrations of $100 \mu \mathrm{M}$ and $5 \mathrm{mM}$, respectively. Procaine and BDM (2,3-butanedione monoxime) were prepared and used on the same day of the experiments.

\section{Triton-skinned fibers experiments}

In protocols using Triton-skinned atrial trabeculae, preparations were obtained and mounted in the same apparatus described above. The experiments were done at $28^{\circ} \mathrm{C}$. The solutions used in these experiments were formulated using a computer program (written in Turbo Pascal language by Prof. Robert E. Godt, Medical College of Georgia) that described the multiple binding equilibrium of ions in solution, using previously given binding constants (13). The solutions contained $1 \mathrm{mM} \mathrm{Mg}^{2+}$, $2 \mathrm{mM} \mathrm{MgATP}, 15 \mathrm{mM} \mathrm{NaCP}$ ( $\mathrm{Na}_{2}$ phosphocreatine), $5 \mathrm{mM}$ EGTA, $50 \mathrm{mM}$ BES [N,N-BIS (2-hydroxyethyl)2-aminoethanesulfonic acid], $200 \mathrm{mM}$ ionic strength [adjusted with potassium methanosulfonate $\left.\left(\mathrm{KmeSO}_{3}\right)\right]$, and had $\mathrm{a} \mathrm{pH}$ of 7.0 . All solutions contained creatine kinase at a final concentration of $1 \mathrm{mg} / \mathrm{mL}$. The $\mathrm{pCa}$ $\left(\mathrm{pCa}=-\log \left[\mathrm{Ca}^{2+}\right]_{\mathrm{o}}\right)$ ranged from 8.5 and greater (relaxing solution) to 4.0 and was adjusted by appropriate addition of $\mathrm{CaCl}_{2}$ and removal of $\mathrm{KmeSO}_{3}$ to maintain an ionic strength at $200 \mathrm{mM}$. The force vs pCa relationship was determined by exposing the trabeculae to this range of $\mathrm{pCa}$. These procedures were conducted in the presence and absence of eugenol to test the effects of the compound on $\mathrm{Ca}^{2+}$ sensitivity of the contractile machinery and maximal force $\left(F_{\max }\right)$.

Experimental solutions were added to one of a series of 3-mL capacity troughs that were milled into a Plexiglas base and stirred continuously. This allowed the transfer of the trabeculae preparations to different troughs in order to expose them to solutions containing a fixed amount of calcium. After mounting, the preparations were transferred to a relaxing solution $(\mathrm{pCa}>8.5)$ and stretched to $120 \%$ of the slack length (zero resting tension). The trabeculae were transferred and incubated for $20 \mathrm{~min}$ in relaxing solution containing Triton $\mathrm{X}-100(0.5 \%, \mathrm{v} / \mathrm{v})$. Following the skinning procedure, the trabeculae were transferred back into the relaxing solution. After $F_{\max }$ had been achieved by exposing the preparation to pCa 4.0, relaxation was obtained by transferring the preparation to the relaxing solution. The force values obtained at each $\mathrm{pCa}$ were normalized to $F_{\max }$. Force- $\mathrm{Ca}^{2+}$ data were fitted to a Hill equation of the following form: $\% F_{\text {max }}=100$ $\left[\mathrm{Ca}^{2+}\right]^{N} /\left(\mathrm{K}^{N}+\left[\mathrm{Ca}^{2+}\right]^{N}\right)$, using a nonlinear least-squares technique. $N$ is a constant related to the steepness of the relationship and $K$ is the calcium concentration required for half-maximal activation.

\section{ATP content of atria muscle}

In another set of experiments, both atria were dissected in Ringer solution. One atrium was transferred to Ringer solution without eugenol and the other to Ringer solution with eugenol. The preparations were kept in 
A

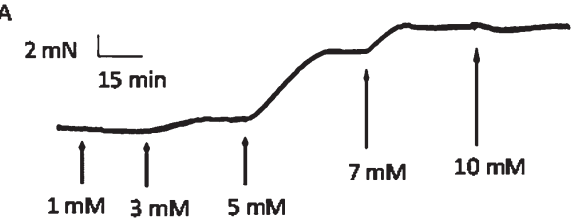

B

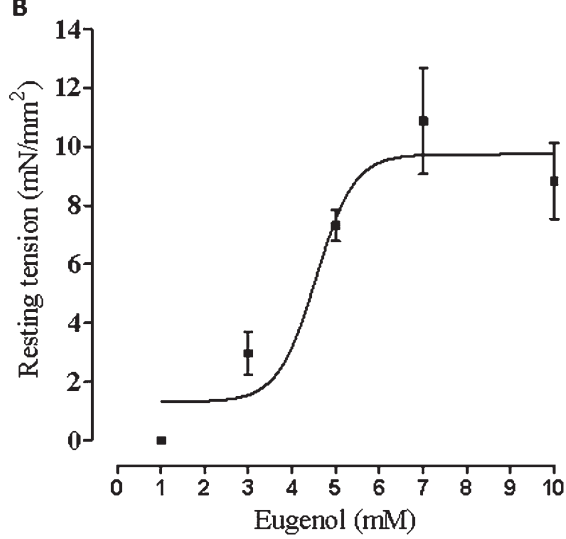

Figure 1. Effect of eugenol on the resting tension of rat atria muscle. A, Typical record of the effect of eugenol at different concentrations $(1,3,5,7$, and $10 \mathrm{mM})$. B, Dose-response relationship of eugenol on the resting tension $(n=6)$.

these solutions for a few seconds (time 0), 30, or 60 min. The preparations were frozen in liquid nitrogen and then weighed. The tissues were suspended in $1000 \mu \mathrm{L} 0.4 \mathrm{M}$ perchloric acid and homogenized. The suspension was centrifuged for $5 \mathrm{~min}$ at $3000 \mathrm{~g}$ at $4^{\circ} \mathrm{C}$. The perchlorate anion was precipitated by addition of $250 \mu \mathrm{L} 1.0 \mathrm{M}$ $\mathrm{K}_{2} \mathrm{HPO}_{4}$ to the supernatant and then removed by centrifugation for $5 \mathrm{~min}$ at $3000 \mathrm{~g}$ at $4^{\circ} \mathrm{C}$. The supernatant was used for ATP measurements using the luciferase enzyme method. To determine luciferase activity, $20 \mu \mathrm{L}$ of each sample was pipetted into a $5-\mathrm{mL}$ polystyrene Falcon tube and read on a luminometer (GloMax-Promega, USA) using the Promega luciferase assay substrate. Tests were done in duplicate. Protein concentrations in $20 \mu \mathrm{L}$ of sample were determined using a BioRad assay (USA). Data were normalized by protein concentration.

\section{Reagents}

Eugenol (purity $=99 \%$ ), ryanodine, BDM, procaine, MgATP, disodium phosphocreatine, EGTA, imidazole, methanesulfonic acid, calcium chloride, and creatine kinase were purchased from Sigma Chemical Co. (USA). All other reagents were analytical grade and were purchased from Merck (Germany).

\section{Statistical analysis}

Results are reported as means \pm SE of at least 6 observations. For multiple comparisons, statistical evaluations were performed using ANOVA followed by the Student-Newman-Keuls test for paired multiple comparisons. Results were considered significantly different from controls when $\mathrm{P}<0.05$.

\section{Results}

\section{Intact atrial trabeculae}

The effect of eugenol on intact atrial trabeculae is reported in Figure 1. Eugenol induced an increase in the resting tension in a dose-dependent manner with an $\mathrm{EC}_{50}$ of approximately $5 \mathrm{mM}$.

Twitch was blocked (80-100\%) by the presence of procaine, ryanodine, or BDM in all electrically stimulated preparations, demonstrating the efficiency of the drugs (results not shown). After 1-2 min exposure to calciumfree Ringer solution, twitch was also abolished. No alteration in resting tension was observed under any of these conditions. The increase in the resting tension induced by eugenol was observed in both normal and calcium-free Ringer solution, as shown in Figures 2, 3,
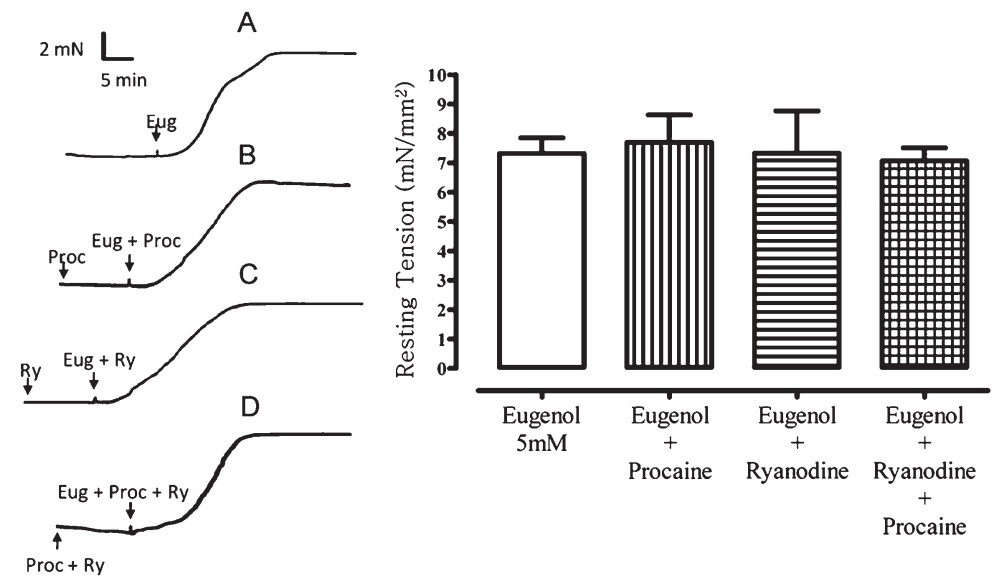

Procaine
Figure 2. Effect of eugenol (Eug) on the resting tension of atria trabeculae of the rat in the absence $(A)$ and in the presence of procaine (Proc) $(B)$, ryanodine (Ry) $(C)$ or both, procaine and ryanodine $(D)$. The experiments were carried out in normal Ringer solution. No significant differences in force were observed among groups $(P>0.05$, ANOVA followed by the t-test; $\mathrm{n}=6$ ). 

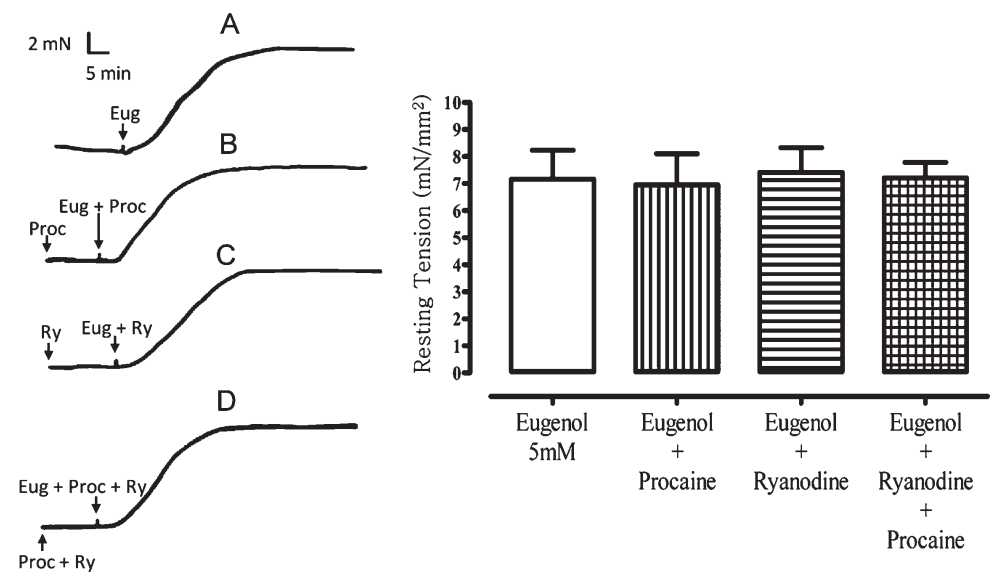

Figure 3. Effect of eugenol (Eug) on the resting tension of atria trabeculae of the rat in the absence $(A)$ and in the presence of procaine (Proc) $(B)$, ryanodine (Ry) $(C)$ or both, procaine and ryanodine $(D)$. The experiments were carried out in calcium-free Ringer solution. No significant differences in force were observed among groups $(P>0.05$, ANOVA followed by the t-test; $\mathrm{n}=6$ ). and 4. The magnitude of this increase was equivalent in both solutions. This effect of eugenol was also observed in preparations previously exposed to procaine and/or ryanodine, either in normal or calcium-free Ringer solutions. In normal Ringer solution containing both procaine and ryanodine, the increase in the resting tension did not differ from control values. However, after 20-30 min, the effect of eugenol on resting tension was completely reversed by exposing the preparation to BDM (Figure $4)$. The effect of BDM was completely reversible. However, 5-10 min after this compound had been washed out, eugenol induced an increase in resting tension. Under all experimental conditions tested, $5 \mathrm{mM}$ eugenol increased the resting tension to $7.318 \pm 0.529 \mathrm{mN} / \mathrm{mm}^{2}$,
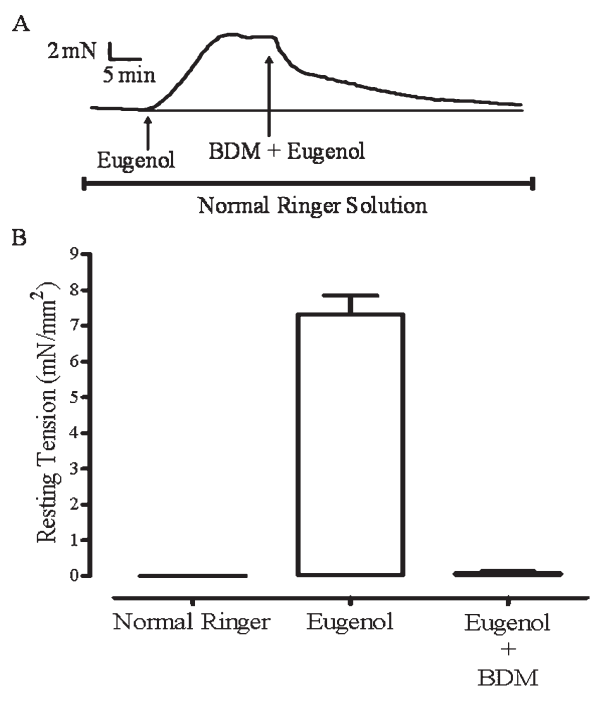

Figure 4. A, Typical chart record showing the effect of $30 \mathrm{mM}$ 2,3-butanedione monoxime (BDM) on the contraction induced by $5 \mathrm{mM}$ eugenol in rat atria. $B$, Data are reported as means $\pm \mathrm{SE}$ of the effect of eugenol and eugenol plus BDM. A significant difference in resting tension was observed $(P<0.05$, eugenol vs eugenol +BDM, Student $t$-test; $\mathrm{n}=6$ ). which corresponded to $118 \%$ of $F_{\max }$.

\section{Triton-skinned atrial trabeculae}

All trabecular membranes were solubilized when exposed to a skinning solution containing Triton X-100; however, the contractile apparatus was kept intact and functional. In preparations skinned with Triton, eugenol was unable to induce an increase in resting tension. Furthermore, eugenol did not alter other parameters (Hill coefficient, $\left[\mathrm{Ca}^{2+}\right]_{50}$, or $F_{\text {max }}$ ) obtained based on the force vs $\mathrm{pCa}$ relationship, as demonstrated in Figure 5 . The values of $\mathrm{N}$ and $\mathrm{Ca}^{2+}{ }_{50}$ in the absence and in the presence of eugenol were $1.37 \pm 0.03$ and $1.60 \pm 0.2 \mu \mathrm{M}$, and $1.18 \pm 0.02$ and $1.24 \pm 0.17 \mu \mathrm{M}$, respectively.

\section{ATP content of atrial muscles}

The concentration of ATP in atrial muscle is shown in Figure 6. Eugenol reduced the concentration of ATP in a time-dependent manner. In the absence or presence of eugenol, the ATP concentrations at 0,30 , and $60 \mathrm{~min}$

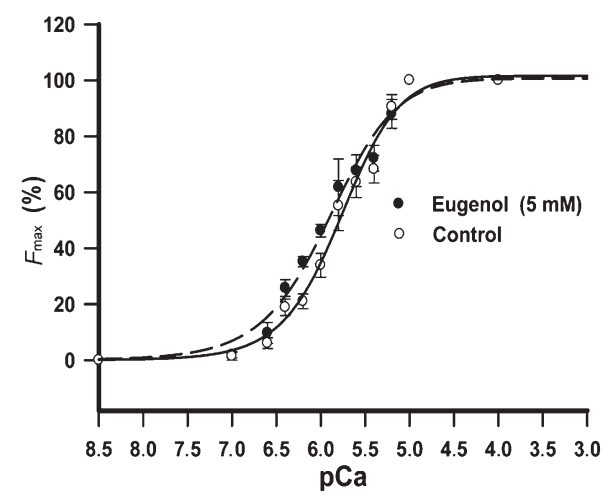

Figure 5. Force-pCa relationship of Triton-skinned atria trabeculae. Force was normalized to $F_{\max }$. Data are reported as average force \pm SE. The values of $\mathrm{N}$ and $\mathrm{Ca}^{2+}{ }_{50}$ in the absence and in the presence of eugenol were $1.37 \pm 0.03,1.60 \pm 0.2$ and $1.18 \pm 0.02$, $1.24 \pm 0.17 \mu \mathrm{M}$, respectively $(\mathrm{n}=6)$. 


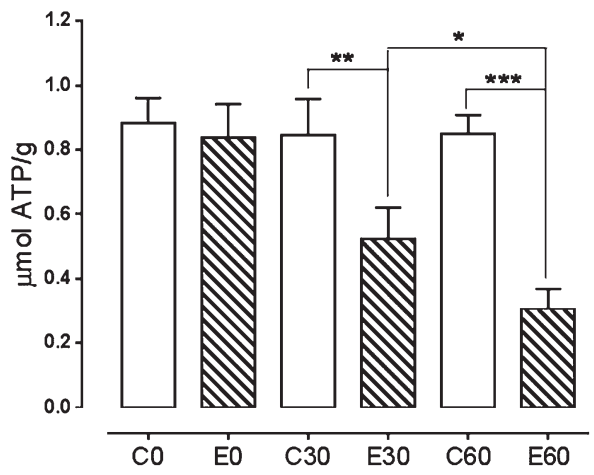

Figure 6. Effect of eugenol on ATP concentration of rat atria. The concentrations of ATP were measured in the absence $(C)$ and in the presence $(E)$ of eugenol at 0,30 , and $60 \mathrm{~min}$. Data are reported in $\mu \mathrm{mol}$ ATP/g protein. $\mathrm{P}<0.05$ (ANOVA followed by the Student $t$-test): ${ }^{*} \mathrm{E} 30$ vs $\mathrm{E} 60 ;{ }^{* *} \mathrm{C} 30$ vs $\mathrm{E} 30 ;{ }^{* * *} \mathrm{C} 60$ vs E60.

were $0.882 \pm 0.036$ and $0.838 \pm 0.047 ; 0.844 \pm 0.051$ and $0.524 \pm 0.044(\mathrm{P}<0.001) ; 0.849 \pm 0.026$ and $0.306 \pm$ $0.028 \mu \mathrm{mol} / \mathrm{g}$ protein $(\mathrm{P}<0.0001)$, respectively. The ATP concentration obtained in our study was one order of magnitude lower than that reported in other studies $(14,15)$. The reasons for such differences are unclear but may have resulted from the use of different species, tissues sample (ventricle vs atria), or techniques. However, in our study, in the same experimental conditions, one atrium was used as a control and the other was exposed to eugenol. This procedure minimized experimental error arising from bias.

\section{Discussion}

In this study, we demonstrated that eugenol increased resting tension in a concentration-dependent manner. Because it has been demonstrated that eugenol blocks an L-type calcium channel (8), and because the increase in the resting tension was not blocked by calcium-free Ringer solution, it is unlikely that this effect was due to calcium inflow. Furthermore, the increase in resting tension likely did not involve calcium released from the SR (through RyR channels) because ryanodine and

\section{References}

1. Fabiato A. Calcium-induced release of calcium from the cardiac sarcoplasmic reticulum. Am J Physiol 1983; 245: C1-C14.

2. Cheng HP, Wang SQ. Calcium signaling between sarcolemmal calcium channels and ryanodine receptors in heart cells. Front Biosci 2002; 7: D1867-D1878, doi: 10.2741/cheng.

3. Cheng H, Lederer WJ. Calcium sparks. Physiol Rev 2008; 88: 1491-1545, doi: 10.1152/physrev.00030.2007.

4. Thompson D, Norbeck K, Olsson LI, Constantin-Teodosiu D, Van der Zee J, Moldeus P. Peroxidase-catalyzed oxidation of eugenol: formation of a cytotoxic metabolite(s). procaine did not block this effect. It appears that its effect was dependent on the proper function of the crossbridges, as the increase of the resting tension induced by eugenol was completely inhibited by BDM, a compound that abolishes muscle contraction by decreasing the attachment rate of cross-bridges, the instantaneous number of attached cross-bridges, and the force generated per attached cross-bridge (16). The increase in resting tension may have been a consequence of the direct effect of eugenol on the contractile apparatus, i.e., increasing calcium sensitivity. However, this is unlikely since eugenol did not change resting tension or the force vs $\mathrm{pCa}$ relationship in Triton-skinned trabeculae. The Triton-skinned trabecula data also exclude the possibility of a deleterious effect of eugenol on the contractile apparatus. Thus, the increase in resting tension cannot be attributed to the extraction of troponin I from the thin filament, which may activate the contractile system. This was confirmed by the observation that eugenol did not induce an increase in resting tension after the membrane solubilization produced by Triton treatment. Because eugenol reduced atrial ATP content, the increase in resting tension observed in intact atria preparations may have been the result of a reduction in the intracellular concentration of ATP. This reduction in the ATP concentration induced by eugenol has also been demonstrated in fibroblasts (14). In isolated rat liver mitochondria, Usta et al. (15) showed that eugenol inhibited NADH oxidase, a proton pumping site, which resulted in a decline in ATP. In skeletal as well as in cardiac muscle, the reduction in the MgATP at a critical level may lead to the formation of both noncycling (rigor, ATP-free) and cycling (ATP-bound) cross-bridges by inducing cooperative activation of the thin filament $(17,18)$. Such a mechanism was inoperative in Triton-skinned atria because the concentration of MgATP in the bathing solution was sufficiently high to avoid noncycling cross-bridge formation. In summary, we found that eugenol induced an increase in atrial resting tension through a mechanism that may have involved cooperative activation of the cardiac thin filaments by strong attached cross-bridges (rigor state).

J Biol Chem 1989; 264: 1016-1021.

5. Michailesco $P$, Kouassi $M$, El Briak $H$, Armynot $A$, Boudeville $P$. Antimicrobial activity and tightness of a DCPD-CaO-based hydraulic calcium phosphate cement for root canal filling. J Biomed Mater Res B Appl Biomater 2005; 74: 760-767, doi: 10.1002/jbm.b.30270.

6. Roberts JF, Attari N, Sherriff M. The survival of resin modified glass ionomer and stainless steel crown restorations in primary molars, placed in a specialist paediatric dental practice. Br Dent J 2005; 198: 427-431, doi: 10.1038/ sj.bdj.4812197. 
7. Clifford MN. Miscellaneous phenols in foods and beverages nature, occurrence and dietary burden. J Sci Food Agric 2000; 80: 1126-1137, doi: 10.1002/(SICI)1097-0010(20000 515)80:7<1126::AID-JSFA604>3.0.CO;2-0.

8. Damiani CE, Moreira CM, Zhang HT, Creazzo TL, Vassallo DV. Effects of eugenol, an essential oil, on the mechanical and electrical activities of cardiac muscle. J Cardiovasc Pharmacol 2004; 44: 688-695, doi: 10.1097/00005344-2004 12000-00011.

9. Sensch O, Vierling W, Brandt W, Reiter M. Effects of inhibition of calcium and potassium currents in guinea-pig cardiac contraction: comparison of beta-caryophyllene oxide, eugenol, and nifedipine. Br J Pharmacol 2000; 131: 1089-1096, doi: 10.1038/sj.bjp.0703673.

10. Magyar J, Szentandrassy N, Banyasz T, Fulop L, Varro A, Nanasi PP. Effects of terpenoid phenol derivatives on calcium current in canine and human ventricular cardiomyocytes. Eur J Pharmacol 2004; 487: 29-36, doi: 10.1016/ j.ejphar.2004.01.011.

11. Leal-Cardoso JH, Coelho-de-Souza AN, Souza IT, Figueiredo IM. Effects of eugenol on excitation-contraction coupling in skeletal muscle. Arch Int Pharmacodyn Ther 1994; 327: 113-124.

12. Lofrano-Alves MS, Oliveira EL, Damiani CE, Kassouf-Silva I, Fogaca RT. Eugenol-induced contractions of saponinskinned fibers are inhibited by heparin or by a ryanodine receptor blocker. Can J Physiol Pharmacol 2005; 83: 10931100, doi: 10.1139/y05-104.

13. Godt RE, Lindley BD. Influence of temperature upon contractile activation and isometric force production in mechanically skinned muscle fibers of the frog. J Gen Physiol 1982; 80: 279-297, doi: 10.1085/jgp.80.2.279.

14. Jeng JH, Hahn LJ, Lu FJ, Wang YJ, Kuo MY. Eugenol triggers different pathobiological effects on human oral mucosal fibroblasts. J Dent Res 1994; 73: 1050-1055.

15. Usta J, Kreydiyyeh S, Bajakian K, Nakkash-Chmaisse H. In vitro effect of eugenol and cinnamaldehyde on membrane potential and respiratory chain complexes in isolated rat liver mitochondria. Food Chem Toxicol 2002; 40: 935-940, doi: 10.1016/S0278-6915(02)00071-6.

16. Bagni MA, Cecchi G, Colomo F, Garzella P. Effects of 2,3butanedione monoxime on the crossbridge kinetics in frog single muscle fibres. J Muscle Res Cell Motil 1992; 13: 516522, doi: 10.1007/BF01737994.

17. Metzger JM. Myosin binding-induced cooperative activation of the thin filament in cardiac myocytes and skeletal muscle fibers. Biophys J 1995; 68: 1430-1442, doi: 10.1016/S00063495(95)80316-4.

18. Kad NM, Kim S, Warshaw DM, VanBuren P, Baker JE. Single-myosin crossbridge interactions with actin filaments regulated by troponin-tropomyosin. Proc Natl Acad Sci U S A 2005; 102: 16990-16995, doi: 10.1073/pnas.0506326102. 